Luka Bekavac

\title{
Otpor materijala: teorijska vlast nad književnim tekstom
}

\begin{abstract}
Bekavac Luka, Otpor materijala: teorijska vlast nad književnim tekstom (Resistance of Material: Theoretical Mastery over the Literary Text). „Poznańskie Studia Slawistyczne" 5. Poznań 2013. Adam Mickiewicz University Press, pp. 31-43. ISBN 97883-232-2636-9. ISSN 2084-3011.

After a brief account of Derrida's notion of singularity as an irreducible, quasi-material layer of (literary) texts, this article attempts to delineate its effects on theoretical or scientific mastery over literature. Invention and law are examined as necessary but mutually cancelling origins of aesthetic and scientific institutions, and the final chapter - following Derrida's Ulysse gramophone - questions the limits of theoretical competence in collision with the incalculable swerve of literarity.
\end{abstract}

Keywords: Derrida; literature; singularity; invention; law; competence; Joyce

\section{Radikalna nečitljivost}

Kada bismo morali odabrati jedan pojam kao čvorište Derridaovih razmišljanja o problemu književnoga teksta i njegove nesvodivosti, izbor bi, možda neočekivano, pao na materiju. Njezina se presudna uloga nazire još u ranim analizama Husserla, a Derrida je u De la grammatologie (Derrida 1974: 87) nerazdvojno povezuje s idejom literarnosti:

prepoznavši specifičnost pisma, glosematika si nije samo podarila sredstva za opis grafičkog elementa. Naznačila je pristup literarnom elementu, onome što u književnosti prolazi kroz nesvodivo grafički tekst, povezujući igru forme s jednom određenom supstancijom izraza. Ako u književnosti ima nečega što je nesvodivo na glas, epos ili poeziju, toga se možemo domoći samo pod uvjetom strogog izoliranja te veze između igre forme i supstancije grafičkog izraza. 
Nasuprot predodžbi književnosti kao utjelovljenja nekog izvantekstualnog smisla, razvija se koncept književnoga djela kao osjetilne tvorbe koja nastaje tek formalnim graviranjem materijalnog supstrata, a prije i izvan toga nema stvarnu egzistenciju. Dosezi djelovanja te materijalnosti ne mogu se reducirati na čistu idealnost, niti do kraja rekonstruirati u bilo čijoj (pa i autorskoj) svijesti; tekst ostaje neukidiv element književne komunikacije u aspektu svoje neinteligibilnosti, pa svakom ekstrakcijom sadržaja iz njega, svakom interpretacijom ili prijevodom na jezik teorije, razgovor o književnosti zapravo prestaje.

„Radikalna nečitljivost (...) prethodi knjizi (u nekronološkom smislu), dakle predstavlja samu mogućnost knjige" (Derrida 1967: 115): na toj će se tezi graditi osebujna materijalistička teorija književnosti čiji središnji pojmovi, poput singularnosti, subjektila, ostatka, stvari, tajne, poematičkoga itd., nisu varijacije jednoga te istoga, no u svojim kontekstima imaju sličnu tendenciju ili funkciju. Ona svoj najopćenitiji oblik pronalazi u ,singularnosti” koju možemo tumačiti trojako: kao pojedinačnost suprotstavljenu općem, konkretnost koja nije bez gubitka prevodiva u čist smisao; kao granicu teorijske pojmljivosti, neprisvojiv „ostatak” svakog iskaza; konačno, kao nemislivu i neopisivu ,graničnu vrijednost” kojoj konvergiraju svi elementi promatranog polja.

„Nerazgradivost” književnih djela leži u neprevodivoj kvazimaterijalnoj jezgri, neznačenjskom višku koji čini recepciju neizvjesnom i nastavlja odgađati moment njezinog iscrpljenja. Pojam tajne, u kasnim Derridaovim radovima neodvojiv od poezije, odnosi se na ono vidljivo, ali nekodirano: „Ima tajne. Ali ona se ne prikriva” (1993b: 60), ne predstavlja neodgonetljiv znak, niti će se razotkriti kao neki uskraćeni sadržaj, manifestirat će se samo neproračunljivim interpretativnim „kretanjem” iz konteksta u kontekst, a njezino će nečitljivo tijelo, uvjet mogućnosti takvoga kretanja, ostati nepromijenjeno. Takva materijalnost nije parcijalan odraz idealnog smisla, nego prostor stvaranja idealnosti: dugoročno djelovanje teksta nije uvjetovano njegovom sposobnošću prenošenja ideje emitenta, nego kapacitetom neinteligibilnih komponenata za provokaciju novih pokušaja idealizacije.

Singularnost teksta podrazumijeva i mogućnost potpunog nestanka; upravo zbog neprenosivosti u druge registre postojanja, „,neznačenjski ostatak" može (i samo on može, jer je sve drugo podložno Aufhebungu) 
biti razoren bez traga. U No apocalypse, not now, Derrida povezuje tu uništivost s književnošću, a prijetnju katastrofom opisuje kao ,,jedini «predmet»svake moguće književnosti, svake moguće kritike, njihov jedini ultimativni i asimbolički referent, nedostupan simbolizaciji, dapače i označavanju" (Derrida 1987a: 379-380). Suočena s krhkim, vječno uništivim, diskurzivno neobradivim ostatkom, književna teorija može samo ,izmišljati stratageme za govor o nečemu drugome" (Derrida 1987a: 379-380), demonstrirati silu pokazujući „što sve možemo učiniti s književnošću”, koristiti književni tekst kao povod ili izgovor za gradnju formalnih konstrukcija u kojima će njezina nadmoć ostati nepomućenom. Umjesto literarnošću kao uvjetom mogućnosti našega postojanja, dakle i potencijalnim okvirom našeg uništenja, kao teoretičari ćemo se radije baviti lateralnim učincima literarnosti, njezinim putevima prema izvantekstovnom, onome što je uvijek lakše komentirati, te što će se, u slučaju nestanka arhiva, lakše rekonstruirati.

Naravno, unatoč tomu što se smisao teksta ne može odvojiti od svoje materijalne utemeljenosti, ona bi bez minimalne čitljivosti ostala posve nedostupnom svakoj percepciji:

Prostor pisma dakle nije iskonski inteligibilan prostor. On to, međutim, počinje postajati od samoga početka, odnosno od trena u kojemu pismo, kao svaki rad znakova, u njemu proizvodi ponavljanje, dakle idealnost. Ako zovemo čitanjem taj trenutak koji odmah dolazi udvostručiti iskonsko pismo, možemo reći da je prostor čistoga čitanja uvijek već inteligibilan, a prostor čistoga pisma uvijek još osjetilan (Derrida 1974: 408-409).

Tim se raskorakom približavamo središnjem problemu naše rasprave: ako je ono literarno u književnom tekstu nesvodivo materijalno, već je elementarno razumijevanje teksta jedan tip ,prijevoda”, pa će svaka teorija, prepričavanje, pa čak i čitanje ,izdati” svoj predložak, utoliko drastičnije što uspješnije ostavi za sobom fizikalnost formulacije izvornika. Kako, dakle, adekvatno teorijski odgovoriti na tu ,singularnost" tekstova?

Timothy Clark (2005: 7) opravdano upozorava na to da nam, u sjeni singularnosti, preostaje samo izbor između repetitivnih truizama i mističkog tonuća u nijemi respekt prema tekstu. Derridaovo suočavanje s njom ipak nije završilo praznom stranicom, nego neponovljivim „supotpisima” Genetu u Glas, Blanchotu u Pas, Pongeu u Signéponge, Celanu u Schib- 
boleth. Međutim, i pojam supotpisa ostaje razapet između dviju nemogućnosti: ako je performativ potpisa znakovni indeks nezamjenljivog „sada i ovdje”, supotpis koji ga pokušava ,poduprijeti” ponavljanjem nužno postaje falsifikat: naše „,nasljedovanje” nekog idioma ima autohtonu vrijednost jedino ako krši njegove zakone te se, paradoksalno, i samo postavlja kao idiomatski iskaz. To znači da moramo ,potpisati kao drugi”, ne krivotvoriti nego neimitativno „izvesti” tuđi tekst - ponovno ga napisati performativom koji će biti neponovljiv poput izvornika. Derrida iskreno konstatira: „To je očito nemoguće” (Derrida 2004: 29), ali singularnost teksta implicira da na pitanje supotpisa ,ne smije biti odgovora u obliku općenite norme, pravila (...), metode ili tehnike koja bi postojala unaprijed" (Derrida 2004: 29-30).

To je najvidljivije mjesto razlike između Derridaovih čitanja književnosti i shematskoga „dekonstrukcionizma”, krutog u svojoj analitičkoj metodologiji te reproduktibilnog u susretu s posve različitim predlošcima. Derridaov će implicitan sukob s različitim tradicijama znanstvenoga proučavanja književnosti, ali i put kojim će krenuti prema problemima zakona i invencije, i dalje proizlaziti iz početnoga pitanja: što je književni tekst ako doista vjerujemo da predstavlja jedinstven jezični fenomen, te kakve to posljedice ima za gospodstvo teorije nad književnošću - teorije koja veliča autonomiju književnosti, no nikada kao granicu vlastite ingerencije?

\section{Invencija i zakon}

Ako inherentna dinamika tekstualnosti ,izigrava (...) sigurnost vlasti (maîtrise)", tada je ,žudnja kritike - koja je također i žudnja filozofije - može, kao takva, samo ponovno pokušati prisvojiti" (Derrida 1993a: 292-293). Nastojat ćemo stoga razmotriti načine kojima različite legitimacijske instancije pokušavaju ovladati tekstovima, te mehanizme kojima tekstovi sabotiraju njihove zakone. U razmišljanju o njihovu odnosu, nezaobilazan je pojam invencije: on crpi snagu iz konflikta tradicije i inovacije, jer ujedno podrazumijeva ,instituciju, zakon, legalnost, legitimaciju” (Derrida 1987a: 15) i ,ilegalnost, kršenje implicitnog ugovora” (Derrida 1987a: 11). Invencija nastaje tek kad i ako postane čitljivom za sustav konvencija, no „kandidira” se za status invencije samo ako - ulazeći u obzor određene 
institucije kao svoje konačne legitimacijske adrese - figurira kao ,protuzakonita", te izmiče kodu koji bi je htio svesti na ono poznato. Štoviše, nije dovoljno da se zatečenim strukturama moći suprotstavi kao negacija: ona mora prekoračiti granice u kojima se te strukture uopće formiraju. Stoga je njezino rodno mjesto privremena zona ,šuma”: postojeći se kod kompromitira ulaskom novog objekta u artikulirano područje; novi kod, gdje će i transgresivni objekt biti samo jedna od poruka, još uvijek nije formuliran; nastaje prostor neodlučivosti u kojemu novi fenomen nije teško samo protumačiti, nego i prepoznati kao cjelinu, budući da će njegova nečitljivost biti prevladana tek stabiliziranjem novoga koda.

Temeljnim problemom postaje legitimacija: opis odnosa u kojemu prvo mora postojati ,zakonodavna” instancija (i nečija kompetencija) kako bi se invencija mogla prepoznati i institucionalizirati, dok ćemo, paradoksalno, svjedočiti invenciji samo ako je ta instancija ne prepozna, ako zbog tuđinstva invencije pretrpi unutarnju promjenu. Pri tomu je najteže razjasniti kauzalno i kronološki ,nemoguć” moment inauguracije, gdje nešto mora biti ujedno čitljivo i nečitljivo, inteligibilno i neinteligibilno, pripadati i ne pripadati sustavu itd. Problem je nesavladiv dok ga promišljamo u okvirima kodova, institucija i estetika kao statičnih, sinkronijskih sustava; u ,praksi” se, međutim, uzastopno sudaraju perspektive staroga sustava i invencije, sve dok ih ne nivelira novi sustav u koji će biti integrirana i invencija. Ona će tako stvoriti „svoje” institucije i kodove čitanja, koji će je ubuduće legitimirati kao regularan dio sustava, sposoban za proizvodnju vlastitih neinventivnih replika.

Unatoč tomu što se, u ovakvoj dinamici invencije, određena razina programabilnosti (odnosno podložnosti patentiranju) doima neizbježnom, Derrida tvrdi kako je invencija ,događaj kojim nam pristiže budućnost” (Derrida 1987a: 40), pa se njezin karakter i režim prispijevanja ne može urediti statutarno: ona nije realizacija neke osviještene mogućnosti, nego prodor u kontekst gdje se nedefinirano stanje ili fenomen, nešto što je za nas „nemoguće”, može ozbiljiti ili barem navijestiti. Naličje te radikalne neproračunljivosti jest ukidanje svih ovlasti subjekta: ako nekakvo ,ja" (individualno, teorijsko, institucionalno) aktivno stvara ili dovodi Drugo kao svoj ,predmet rada”, možemo biti sigurni da to nije Drugo. Smisao invencije i njezinoga kapaciteta puštanja ,potpuno drugoga" da priđe zapravo je u tomu što će njezin učinak ostati trajno nedostupnim potpunoj 
kodifikaciji i dijalektičkom prisvajanju putem razumijevanja ili prijevoda: poput književnoga teksta, ona ,čini više nego što govori i stvara nešto povrh onoga što daje patentirati" (Derrida 1987a: 58). Kako je najvidljivije u slučaju kanonskih, „,vječnih”, ,velikih” djela, koje kulturne institucije nastoje najsnažnije osvojiti i umrtviti, u tekstu uvijek nastavlja djelovati nekodirana jezgra singularnosti, nedostupna zakonu.

Sustav zakona kompenzira općenitost svojih iskaza djelotvornošću u velikom broju situacija, no iza lažne ideje empirijske ,nepredvidljivosti” (za koju se pretpostavlja da će biti svodiva na parametre zakona) zakon postaje apriornim rasterom mogućega, ,vokabularom postojanja” koji će unaprijed isključiti sve neprevodivo na njega. Univerzalnost jezika kao sučelja zapravo dokida singularnost idiomatskih tvorbi: sve svojstveno određenoj sintagmi bit će uništeno prolaskom kroz filter zakona. Ako je pravda ono heterogeno, nesvodivo na ,primjenu pravila, pokretanje programa, izradu računa" (Derrida 2005: 50), teorijski pristup inventivnom tekstu ne može ostati na razini rada starog formalnog stereotipa na novom materijalu. Čin čitanja i sam mora „,inventivno” razriješiti paradoks transgresije zakona, i to iznova u svakom pojedinačnom slučaju, pa stoga niti ne može proizaći iz postojećega teorijskog fonda - on je nužan raskid s kognitivnim parametrima koji mu prethode. Nije riječ o pukoj odsutnosti pravila ili znanja o njima, nego o djelovanju bez jamstava disciplinarnih ili filozofijskih sustava, kojim će se pravila reinstituirati u skladu s invencijom.

Događaj singularnosti već predstavlja budućnost u trenutku u kojemu ona još nije pristigla, niti je možemo dosegnuti ekstrapolacijama utemeljenim u pozitivnom stanju. U tom je smislu književni tekst, sa svojim nečitljivim nesvodivostima i ,greškama” u očima poetike, sintagma nastala prema kodu à venir. Poremećena temporalnost, „futur drugi” teksta koji će svoju inteligibilnost pronaći u „budućnosti”, zapravo predstavlja ključ njegove autonomije: svaki je inventivan tekst implicitna referencija na kod koji još ne postoji, sintagmatska realizacija mogućnosti tog koda koja u polju u koje dolazi - mora ostati djelomice neshvatljivom. Međutim, inovacija nije svodiva na naše recepcijsko kašnjenje za „inauguralnim” trenucima, realizacijama koda koji u našem prezentu još nije kulturno arhiviran. Takva bi „invencija” bila učinak našeg interpretativnog rada: ostali bismo u teorijskim okvirima strukturalizma, a formuliranje gramatike književnosti predstavljalo bi samo pitanje vremena i truda. Aspekt 
nečitljivosti koji opstaje u književnom tekstu ne može se prevladati refleksivnim sudom jer ga singularnost osjetilnoga čini načelno neprenosivim u pojam. Interakcija materije i inventivnog formalnog djelovanja stvara specifičnu sferu interferencije osjetilnog i inteligibilnog, jedinstvenu i neponovljivu u svakom konkretnom tekstu, koja se nikada neće u potpunosti razriješiti u korist ,tupe" materijalnosti niti u korist transparentne čitljivosti: ta sfera se zove književnost.

Pitanje o tomu ,tko odlučuje, tko sudi, i s kakvim ovlastima, o tomu što pripada književnosti” (Derrida 1992: 188) bit će u središtu alegorijskoga teksta Ispred zakona, posvećenog analizi istoimene Kafkine minijature. Ako „bit” književnosti, kao i mogućnost dosljedne klasifikacije tekstova, izostaje zbog njihove sposobnosti generiranja sloja koji se neće moći pročitati, asimilirati ili anticipirati (odnosno prikazati kao manifestacija zakona), svaki će teorijski iskaz koji želi doista odgovoriti na "provokaciju” teksta morati i sam težiti ostvarenju neizvodive mathesis singularis. Prihvatimo li inventivnost i inicijalnu ,nevidljivost” i „nepredstavljivost” za postojeći zakon kao uvjete mogućnosti književnoga teksta, njegov će se zakon uvijek inaugurirati jednokratno i a posteriori. Kafkina pripovijest završava zatvaranjem vrata zakona jer su ona bila otvorena samo za čovjeka sa sela: „idiomatski” će se zakon artikulirati samo prema svojem singularnom predmetu, a ako do susreta s njim ne dođe, neće biti ni manifestacije zakona. Singularan zakon tog tipa po definiciji ne može biti eksplicitan i aprioran: bit će takav samo kad ga instrumentalizira teleologija određene estetike, tržišne ili političke opcije, dok on kao takav nema ,preferenciju” kojom bi priječio bilo kojem tekstu pristup svojem prostoru minimalne artikulacije i inteligibilnosti. Samo historijski ograničene poetičke pretenzije na tekst imaju razlog za kodifikaciju lijepoga, dok sam zakon, poput Suda u Proce$s u$, zapravo od teksta ništa ne "traži” - a najmanje to da se mijenja kako bi mu se otvorio pristup legitimaciji. Glavno oružje personificiranog pozitivnog zakona je forsirana odgoda: on uvijek radije ignorira invenciju i govori „ne još”, time prikrivajući izvor svoje vlasti, jer ima status zakona samo po svojoj sinkroničnosti. Zato za zakon nikada neće doći „pravo vrijeme”, a književnost ne može doživjeti inauguralni moment čekajući da je on pripusti u svoje okvire: na njoj je jednostavno da se dogodi i tim neprogramiranim nastankom postane jedini i konačan akt novog zakona. 
Književnost je tako specifičan oblik angažmana idiomatskog $s$ kategorijalnim: „zacijelo se ne bi moglo govoriti o «literarnosti» kao o pripadanju književnosti, inkluziji fenomena ili objekta, čak niti djela, u neko polje, domenu, regiju čije bi granice bile čiste a naslovi nedjeljivi. Djelo, opus, ne pripada nekom polju, ono je transformator tog polja" (Derrida 1992: 215). Književni će tekst, dakle, biti ono čijem mediju - neodvojivom od „sadržaja” - prijeti mogućnost apsolutnog uništenja bez ostatka, a zatim i ono što ne može pripadati određenom postojećem skupu, kodu, polju ili zakonu, nego ga može samo uspostaviti ili preobraziti. „Nije li potrebno, za svaku književnost, da premaši književnost? Što bi bila književnost koja je samo to što jest, književnost? Ona više ne bi bila to što jest da je to što jest" (Derrida 1992: 215). Nema, međutim, teorije koja će moći s lakoćom prevesti taj zaključak u praksu.

\section{Kompetencija i clinamen teksta}

Problemi invencije i zakona omogućili su skiciranje uvjeta pod kojima književni tekst, iz pretpostavljene nedohvatne singularnosti, postupno prelazi u domenu čitjivosti i raspoloživosti različitim recepcijskim instancijama. Među radovima koji se bave naknadnom uspostavom institucionalne kontrole nad književnim tekstom, posebno mjesto ima Uliks gramofon čija je temeljna tema napetost između slučaja i nedeterminiranosti s jedne strane, te zakona i programa s druge. Nedeterminiranost ne implicira relativizam i proizvoljnost, nego netrasiranost diseminacijske putanje kojom će se „,neznačenjski minimum” razvijati kroz determinirane kontekste interpretacije: nemoguće je unaprijed ,skriptirati” supotpise koji čine recepciju teksta, jer oni ne postoje prije vlastite izvedbe.

Stoga u raspravu ulazi clinamen. „U Lukrecijevoj kozmologiji, predfenomenalno, iskonsko stanje nediferencirane tvari predstavljeno je kao beskonačan vodopad atoma" (Johnson 1993: 134), a u njemu će clinamen kao „neznatna skretnja” (Lukrecije 2010: 51), slučajan i nemotiviran otklon u strogo linearnom kretanju čestica, imati presudnu važnost. Kao faktor nepredvidljivosti i otpora determinizmu, za Derridaa je clinamen apsolutno impersonalan: ne predstavlja rezultat djelovanja nečije volje na pasivnom predmetu, nego pokret kojim materija uvijek ,prestiže”, nad- 
jačava i motivira djelatnost subjekta, onemogućujući svođenje pisma na izvantekstualne programe. Takvo „događajno vibriranje” materijalnosti teksta, koje nije unaprijed iscrpivo nekom teorijskom pozicijom, vodi nas temi kompetencije i njezine uloge u normiranju čitanja tekstova. Primivši poziv na simpozij o Joyceu, Derrida pretpostavlja da mu je uloga govornika prepuštena zlonamjerno, samo kako bi razotkrio svoju nekompetenciju, površnost svojega poznavanja Joycea (Derrida 1987b: 95). Kao „gost”, dakle tuđinac, poslužit će kolektivu za jačanje njegova identiteta; istinski kvalificiran govor može doći samo iz unutarnjosti kolektiva, kao tautološka potvrda njegova sveznanja.

Postavlja se, dakle, pitanje: što je uopće stručnjak, ako ta riječ podrazumijeva duboko poznavanje područja, vladanje njegovim kategorijama i granicama, potpun nadzor nad mogućnostima njegova funkcioniranja? Derrida tvrdi da je sam Joyce kalkulirano nastojao projektirati instituciju koja će imati posla stoljećima nakon njegove smrti, organiziranu poput „moćnog stroja za čitanje, potpisivanje i supotpisivanje u službi njegova imena, njegova patenta" (Derrida 1987b: 77). Zbog jaza između imena i patenta, ta je institucija načelno ,nemoguća i nevjerojatna" (Derrida 1987b: 77), do granice urušavanja koncepta kompetencije na kojemu se temelji njezin legitimitet. Patent nalaže da ga poštujemo, slijedimo i reproduciramo; ime, s druge strane, onemogućuje reprodukciju i prijevod, a svaki pokušaj poništavanja napetosti među tim ekstremima predstavlja samo falsificirano ekspertski (zapravo povijesno i interesno fiksiran) čin zastrašivanja autoritetom, pokušaj ,zaustavljanja diseminacije”. U nedostatku prostora, samo ćemo podsjetiti na još dva pokušaja inhibiranja događajnoga karaktera inskripcije, kojima se Derrida ekstenzivno kritički pozabavio: Lacanov rad, gdje se tradicionalan psihoanalitički nehaj prema literarnosti udružuje sa strukturalističkom redukcijom sintagmi na dubinske strukture, te teoriju govornog čina - u Searleovoj redakciji - čija obrana vlastite baštine pred „,neovlaštenim” čitateljima poprima gotovo klerikalne ili kaznene forme.

„Uliks gramofon” dovodi u pitanje tu ideju „totalnoga znanja” o (Joyceovu) tekstu, pretpostavljajući da si ga pripisuju pripadnici International James Joyce Foundation. Subjekt koji tvrdi da posjeduje takvo znanje automatski se postavlja u poziciju kontrolora tuđih analitičkih pristupa (koji su tada ili reprodukcije institucionalno verificiranih pristupa, ili puke 
greške i promašaji), ali onemogućuje nastavak djelovanja samoga teksta. Naime, ako tekstu glavni zamah osigurava upravo „nečitljivi ostatak” kao energent iterabilnosti i diseminacije, ujedno kao jamstvo stanovite „budućnosti”, netko tko bi tvrdio da - makar samo u nekakvom „danom trenutku” - posjeduje apsolutno znanje o određenom tekstu, potpuno gospodari njime (u smislu da mu je tekst u cijelosti „dostupan” kao mentalno prezentan idealitet koji se asimilira bez ostatka), načelno bi nijekao svaku mogućnost interpretativnog mobiliziranja teksta izvan okvira vlastitoga znanja. Svođenjem teksta na ograničen skup prevodivih i poopćivih formi nestala bi povijesnost kao takva: cjelokupna empirijska povijest interpretacije bila bi samo „popunjavanje kućica” u općem programu znanja-o-tekstu koje je nastalo simultano s njim i nastavilo koegzistirati kao njegov idealni korelat. Pod takvim bi kvazipovijesnim procesom akumulacije znanja konačnu crtu podvukao upravo subjekt koji sebe proglašava ekspertom.

Derrida ukazuje na kritično mjesto filozofije koja bi branila takvu stručnost: svakim subjektivnim činom podvlačenja i prisvajanja negiralo bi se postojanje onog minimuma materijalnosti pisma koja je potrebna već i za puko konstituiranje idealnosti. Ako i prihvatimo mogućnost da u svakoj znakovnoj artikulaciji doista postoji nekakav konačan ,program” djelovanja, ne možemo ga pojmiti kao sadržaj do kojega bi, probijanjem koda, mogao doći bilo koji konkretan analitičar, zatvorivši time zauvijek potrebu za proučavanjem materijalnosti teksta: upravo ona, tuđa subjektu, izvan dosega njegove moći, predstavlja medij u kojemu je enkriptiran taj program, ali ne kao spoznatljiv kod; njegovo je izvršenje u svojim procedurama nedeterminirano, a u svojem trajanju i eshatološkoj perspektivi ograničeno samo vlastitim nestankom, odnosno nestankom svijeta. U svakom drugom slučaju, stvarna bi povijesnost bila nemoguća: istinski bi postojala samo idealna statika prije stvaranja.

Derrida pronalazi argument protiv ideje institucionalne iscrpivosti Joyceova teksta u spomenutoj činjenici da se projekcija višestoljetnoga rada na njemu mogla odnositi samo na neke buduće sveučilišne modele kakvi u trenutku pisanja nisu postojali. Mobilizacija velikih grupa ljudi, resursa i tehnologije u pothvatu izgradnje novih institucija tipična je za sve „Maîtres-Penseurs" (od Platona do Heideggera i dalje) koji djeluju s odgodom, uvijek stvarajući figurativni poste restante, a ne eksplicitan ,politički” naputak namijenjen nekoj konkretnoj i njima suvremenoj kulturnoj 
aktualnosti. Njihova veličina nije u utemeljiteljskoj ulozi, ,spomeničkom” privilegiju predaka od kojega žive drugorazredne i interesno vezane institucionalne hijerarhije: ona je u potpuno nepredvidljivoj sposobnosti pokretanja procesa kojima će se generirati budućnost kakva se, u trenutku nastanka njihovih tekstova, nije dala anticipirati. Tako je Joyce, prema Derridau (Derrida 1987b: 96), predvidio i iskoristio globalizaciju, svjetsku dominaciju kapitalizma, teletehnologije i nove oblike arhiviranja.

Joyce dovodi eksperte u nerješivu situaciju: oni rade na izgradnji superkompetentne točke gledišta, čiji se pisani korpus, kako bi dostigao Uliksa, mora praktički izjednačiti sa sadržajem svih znanosti kojima se bavi sveučilište; riječ je o hiperboličkoj kompetenciji u odnosu na koju ništa ne bi bilo transcendentno (Derrida 1987b: 100). U Dvije riječi za Joycea Derrida piše o Joyceovu radu kao konstrukciji ,hipermnezijskoga stroja" koji bi nas trebao unaprijed proračunati i kontrolirati, zabraniti nam mogućnost inauguriranja novoga, budući da je već sve zapisao on sam: „ne možete reći ništa što već nije programirano na tom kompjutoru tisućite generacije, Uliksu, Finneganovu bdijenju, prema kojemu aktualna tehnologija naših mikrokompjutorskih arhiva i prevoditeljskih strojeva ostaje krparija, igračka prethistorijskoga djeteta" (Derrida 1987b: 22).

Ključ kojim eksperti, kao samozvani vlasnici ili predstavnici (ali ne i „programeri”) tog superkompjutora, zastrašuju sve koji ne pripadaju njihovoj obitelji ujedno dovodi u krizu temelje njihove kompetencije; oni navodno raspolažu apsolutnim znanjem u ograničenom polju, no i sami su tek učinak tog znanja.

Joyceov ,potpis”, temelj i predmet cijeloga korpusa joyceologije, ostat će element nepredvidljive i nesvodive izvanjskosti koja nikada neće moći biti uključena u taj korpus, bez obzira na navodni totalitet kojim će raspolagati njegov krovni uređaj. Taj sveinkluzivni ,alfa i omegaprogramofon u kojemu bi sve povijesti, sve pripovijesti, diskurzi, znanja (...) bili preskribirani, unaprijed izračunati onkraj svakoga zbiljskog kompjutora, unaprijed obuhvaćeni, zatočeni, proreknuti, parcijalizirani, metonimizirani, iscrpljeni, poput predmeta, znali to oni ili ne" (Derrida 1987b: 117), ostaje ideal jedne načelno neostvarive svemoći koja želi proširiti svoje okvire do granica spoznatljivosti same. Znanost o književnosti ne može u potpunosti asimilirati materijalni sloj tekstova: ako je putanja Joyceova djela načelno neproračunljiva, nemoguće je „danas” procijeniti apsolutnu relevantnost 
bilo kakve znanstvene djelatnosti za Joycea. Spomenuti „nad-kompjutor” ne može pročitati neeksplicirane, ,vibracije" teksta jednostavno zato što one nisu nerealizirane mogućnosti poznatoga koda, nego nepredvidljive formacije, događaji koji nastaju tek kontingentnim susretima, odgovorima ili supotpisima. Tako mišljen događaj ,potresa sam pojam kompetencije” (Derrida 1987b: 108): arbitrarno zatvaranje okvira čitanja uspostavlja kompetenciju-kao-moć, no nikada neće ,prestići” diseminacijski tijek teksta.

Sila kojom književni tekstovi djeluju mimo svake teorijske ili kulturne paradigme i mode, svakog "horizonta”, čini znanstveni model impliciran Uliksom ,grimasom hiperučenosti” (Derrida 1987b: 118), karikaturom želje za apsolutnom kontrolom koju je nemoguće nametnuti nedeterminiranom djelovanju teksta. Ideal hipermnezije ne može se ostvariti upravo zbog literarnosti kao posve reduciranog, neznačenjskog sloja; zbog toga je „sam diskurz kompetencije (diskurz neutralnog i metajezičnoga znanja, zaštićenog od svakog neprevodivog pisma itd.) nekompetentan, najirelevantniji mogući diskurz kad je riječ o Joyceu koji se, uostalom, i sam nalazi u istoj situaciji svaki put kada govori o svojem djelu" (Derrida 1987b: 108). Relevantan iskaz o nedohvatnom književnom tekstu moći će doći samo kroz drugoga, neproračunljivo, ,čudovišno” za sustav ili „,kompjutorski program", i to ne u ruhu sistemskoga, nego pojedinačnoga i nesvodivoga, kao jedan odgovor koji će svojom singularnošću i sam izmaknuti „telefonskoj centrali”, ,ranžirnoj stanici, mreži kojom moraju putovati sve informacije" (Derrida 1987b: 106), odnosno ideji znanosti o tekstu koja će i dalje imati savršenu kompetenciju i apsolutnu ingerenciju - u svojim granicama.

\section{Literatura}

Clark T., 2005, The Poetics of Singularity: The Counter-Culturalist Turn in Heidegger, Derrida, Blanchot and the Later Gadamer, Edinburgh.

Derrida J., 1967, L'écriture et la différence, Paris.

Derrida J., 1974, De la grammatologie, Paris.

Derrida J., 1987a, Psyché: Inventions de l'autre, Paris.

Derrida J., 1987b, Ulysse gramophone: deux mots pour Joyce, Paris. 
Derrida J., 1992, Before the Law, u: Acts of Literature, prev. A. Ronell, C. Roulston, New York-London, str. 183-220.

Derrida J., 1993a, La dissémination, Paris.

Derrida J., 1993b, Passions, Paris.

Derrida J., 2004, Countersignature, prev. M. Hanrahan, „Paragraph 27” br. 2, str. 7-42.

Derrida J., 2005, Force de loi. Le „Fondement mystique de l'autorité”, Paris.

Johnson C., 1993, System and Writing in the Philosophy of Jacques Derrida, Cambridge.

Lukrecije, 2010, O prirodi, prev. M. Tepeš, Zagreb. 
